\title{
Resenha: Um mundo sem livros e sem livrarias?
}

\author{
Review: A world without books and libraries?
}

José Teófilo de Carvalho (iD $* 1$

${ }^{1}$ Centro Federal de Educação Tecnológica de Minas Gerais, Belo Horizonte, MG, Brasil.

\author{
CHARTIER, Roger. Um mundo sem livros e sem livrarias? Edição: GUIOMAR DE \\ GRAMMONT. 1. ed. São Paulo: Letraviva, 2020
}

Um mundo sem livros e sem livrarias? é o título do livro mais recente de Roger Chartier, lançado no Brasil pela Editora Letraviva. Coordenada por Guiomar de Grammont, que escreve também o prefácio, a obra reúne artigos de conferências e de pesquisas desse conhecido autor francês, realizadas em universidades e em instituições ligadas ao mercado editorial, nas duas últimas décadas. O livro contém prefácio, seis capítulos - a maioria escrita em português - e epílogo com análises de pesquisas publicadas recentemente nos mercados editoriais francês, norte-americano e brasileiro.

O título traz um questionamento sobre o destino do livro impresso, nos aspectos relacionados às suas diversas manifestações e processos, hoje, em transição para meio digital. Nessa obra, o autor discute três transformações relacionadas ao livro na sociedade atual: mudança na forma de escrita e de leitura - do meio impresso para o digital; a redução gradual do número de leitores e de livros impressos; como consequência, a repercussão desses fatores na produção editorial e na forma de distribuição. Desse olhar atento de historiador, surgem novas teorias e hipóteses sobre o futuro da escrita, da leitura e das livrarias físicas.

Além disso, Chartier retoma também as transformações do texto, em seu sentido amplo, relacionandoas à evolução do suporte de leitura - do antecedente rolo ao codex, desse à prensa de papel e, atualmente, do papel para a tela. Para esse autor, a primeira e a terceira transformações são revolucionárias, porque mudaram e mudam a encenação da leitura - gestos, postura corporal e concentração no texto - a segunda, por sua vez, é apenas uma evolução da técnica de produção, introduzida pela prensa de Gutenberg no século XV.

Nesse contexto, o prefácio já adianta alguns pontos de discussão do livro, relacionando-os às obras anteriores do autor, cujos temas giram em torno das inquietações que dão nome a esse compêndio.

O capítulo inicial - A morte do livro? - é o tema de uma conferência, pronunciada em espanhol, no Fórum das Letras da UFOP em 2006. O autor faz um diagnóstico e aponta as diferenças entre o livro impresso e o digital. Porém, afirma que o futuro do digital se tornou, hoje, incerto e aponta algumas razões para isso, como, por exemplo, as práticas de leitura e de escrita produzidas pela digitalização - leitura superficial, rápida e descontínua.

Antes, porém, de responder à pergunta do título desse capítulo, a autor faz outra: o que é um livro? Como resposta, recorre a vários conceitos, entre os quais aponta o da Metafísica dos Costumes, de Kant, que distingue duas dimensões de um livro: como objeto material, pertencente a quem comprou, e como discurso dirigido ao leitor, cujo proprietário é o autor. Chartier cita Borges que, em 1952, dizia: "Um livro é mais que uma estrutura verbal, ou que uma série de estruturas verbais; é o diálogo que trava com seu leitor e a entonação que impõe à voz dele e as imagens mutantes e duráveis que deixa em sua memória. [...]" (BORGES, 2012 apud CHARTIER, 2020, p. 57). Insensível à materialidade da obra, o que importa para Borges (2012) é a leitura do texto, cujo sentido é apropriado pelo leitor e não o objeto de papel.

Chartier pensa diferente. Para ele, em linguagem metafórica, é como se o livro tivesse corpo e alma, por isso justifica a pergunta sobre a morte do livro. Recorrendo a várias teorias — Filosofia, Direito, Literatura e Linguística - infere que o livro não morrerá como discurso; mas, sim, como objeto de leitura. Tal percurso, no entanto, vai depender das novas tecnologias da tela, dos hábitos e das expectativas dos leitores que dialogam com as obras por meio do pensamento e dos sonhos.

${ }^{*}$ Email: jteofilo.carvalho@gmail.com 
O segundo capítulo, Edições científicas, foi apresentado em um evento sobre o livro digital na Embaixada do Brasil na França em 2014. O autor apresenta a estagnação do mercado de livros digitais nos últimos seis anos e aponta vários motivos para esse fenômeno. Um deles é o conflito entre a lógica intelectual, que exige livre acesso ao conhecimento e compartilhamento do saber, e a lógica comercial, baseada nos conceitos de propriedade intelectual e nas regras de mercado. Ressalta ainda que o leitor passou a controlar as interpretações e a ter acesso às "provas" científicas e aos dados que são utilizados na argumentação do pesquisador.

Esse autor recorre às definições do capítulo anterior e discute a tensão entre a imaterialidade das obras e a materialidade dos textos, a mesma que caracteriza a relação entre os leitores e seus livros, dos quais não são críticos nem editores. Todavia, reconhece que, ao se apropriarem de um texto, os leitores se tornam coautores e dão-lhe novo sentido. Talvez, seja essa relação uma das motivações da pesquisa acadêmica.

Em seguida, o autor expõe a multiplicação das editoras universitárias no século XX, as transformações culturais nos hábitos de leitura e de compra de livro dos franceses entre 1973 e 2008 . A essas se somam as mudanças nas práticas de leitura — falta de hábito de ler na faixa de 15 a 19 anos, mais recursos digitais, repasse de livros, cultura da fotocópia - levando à diminuição na compra de livros na faixa etária entre 19 e 25 anos. Nesse cenário, o leitor de texto científico ainda prefere o texto impresso, porém multiplicam-se diariamente os textos digitais.

O capítulo seguinte - Livrarias - foi exposto em 28 de agosto de 2019 na conferência de abertura na 29 a Convenção Nacional de Livrarias, durante a Bienal do Livro do Rio de Janeiro. Como não podia deixar ser, o tema em discussão desse evento era o movimento de fechamento de livrarias em todo o mundo, devido ao crescimento exponencial de vendas de livros pela Internet.

Nesse evento, o autor apresenta estatísticas dos mercados editoriais francês, americano e brasileiro e realça o fenômeno das vendas on-line pelas editoras e distribuidoras, mercado monopolizado pela Amazon. Para o autor, as livrarias sobreviventes, com espaço de leitura ao fundo, são utopias. A força das utopias e dos sonhos, entretanto, pode inspirar decisões institucionais, ações coletivas e condutas individuais, as quais evitarão um mundo sem livrarias.

No quarto capítulo, denominado de Autoedição, Chartier utiliza um texto de uma palestra, apresentado na Universidade Sta. Úrsula em 2019. Resgata a história das práticas autorais, da antiguidade aos dias atuais, ressaltando que as edições autorais eram mais difíceis no passado. Por isso, ele entregava as tarefas, da produção à distribuição, ao editor. No entanto, o mundo digital muda a relação entre autores e seus leitores, graças à Web, e facilita a autoedição; até porque a produção, na atualidade, se dá sob demanda. A autopublicação é, portanto, uma maneira de inventar novas formas discursivas e pode ser a ressurreição do autor, cuja morte se prenuncia desde o século XX.

Ler sem livros é o título do quinto capítulo, no qual o autor traz à memória lembranças de suas leituras na adolescência. Num texto produzido em espanhol, a pedido da revista eletrônica Alabe, afirma ainda que escrever lembranças pessoais é sempre produzir (conscientemente, ou não) uma representação do passado imaginado, desejado, e não o que aconteceu realmente. Logo, escrever sobre a memória dos leitores se tornou um verdadeiro gênero literário na atualidade.

Chartier distingue, também, o leitor nascido em um mundo saturado de livros daquele nascido em um mundo sem livros e reconhece o papel que a escola desempenha na formação desse último, local onde o estudante aprende a ler. Nesse caso, a leitura é uma conquista. No entanto, o autor admite novas modalidades de leituras sem livro, prometidas e impostas pelas telas do mundo digital. Recapitula também algumas obras do século XVI e XVII, as quais já indicavam a possibilidade de outras formas de narrativas, como a icônica, a partir da teoria renascentista da equivalência entre discurso e imagem; escritor e pintor.

O pesquisador lembra ainda que a palavra "leitura" está associada à ideia segundo a qual a prática de leitura vai além da apropriação da escrita. Como justificativa para sua posição, utiliza, como exemplo: A importância do ato de ler, de Freire (1989), para quem ler supunha, primeiro, alfabetização e os sentidos de "ler" poderiam significar ler letras, palavras ou livros, mas também "ler" o mundo, a natureza, a memória, os gestos, os sentimentos. Designava esse sentido aberto da leitura com o neologismo 'palavramundo'. 
Por fim, Chartier discute, como primeiro desafio ao leitor, o significado ampliado de texto e se sua compreensão deve ser pensada como uma leitura. Nesse debate, admite a possibilidade de ler sem livros; porém, citando Marin (1993), nos adverte contra a tentação de pensarmos que podemos ler imagens na tela, por exemplo, como se lêssemos textos (nesse caso, texto verbal). O segundo desafio é a leitura fragmentada, descontextualizada e superficial na tela: "A digitalização do mundo é uma magnífica promessa e, ao mesmo tempo, uma perda se ignora ou se apaga as heranças que permitiram e ainda permitem múltiplas experiências do ler e do escrever" (CHARTIER, 2020, p. 166-167). Uma dessas heranças é a existência de uma forte relação com a totalidade textual e com cada um de seus elementos constituintes.

O último capítulo, Experiências brasileiras, apresentado na Jornada Intercultural França-Brasil, em julho de 2019, mostra uma pesquisa sobre três autores franceses que trabalharam no Brasil Fernand Braudel - ou que visitaram o país várias vezes - Michel de Certeau e Michel Foucault —, acrescido de Pierre Bourdieu. Esse último nunca viajou ao Brasil, mas manteve fortes relações com a realidade e com sociólogos brasileiros, nos campos da educação, da sociologia dos esportes e da história dos intelectuais. Os autores escolhidos, constituem apenas um recorte de vários pesquisadores franceses que estiveram ou trabalharam no Brasil. Esse é o capítulo menos alinhado às discussões da obra, cujo tema central é o livro, acrescido da leitura e a escrita em outras formas de textos, em transição hoje do impresso para o digital.

Para finalizar, Chartier retoma o tema do livro com um epílogo: Um mundo sem livros e sem livrarias? Texto escrito, especificamente, para a obra publicada, mostra que, no mundo digital, se lê cada vez mais sem livros. O autor atualiza ainda dados de pesquisas francesas anteriores, de 1973 a 2008, com três observações: 1) o número de leitores de livros vem caindo sistematicamente nas últimas gerações; 2) a porcentagem de leitores constantes e bons compradores de livros acompanha a tendência, no geral, mas revela uma inversão do público masculino para o feminino; 3) o percentual de indivíduos que se dizem em um sistema totalmente digital vem aumentando, principalmente entre os mais jovens. As pesquisas no Brasil apontam no mesmo sentido e a venda de livros vem caindo na última década. A questão é: será que esse universo permanecerá sempre juvenil? Vale lembrar que a comercialização de e-books representa menos de $10 \%$ de vendas de livros na Europa, nível semelhante ao do Brasil, e um pouco mais alto no mercado norte-americano.

Pela atualidade das discussões e pertinência das reflexões, esta obra merece uma leitura atenta dos profissionais interessados na produção de textos, na leitura e no mercado editorial. Os capítulos, muitas vezes, atualizam conceitos já discutidos por Chartier em publicações anteriores e podem ser lidos em qualquer ordem, por terem princípio, meio e fim. É preciso pontuar que este livro não esgota o tema. Além disso, a obra traz, também, dicas de leitura para pesquisadores, autores, editores, professores, estudantes de pós-graduação e de graduação que têm o livro como objeto de pesquisa ou de trabalho, seja como suporte de leitura, discurso ou texto. Afinal, são esses profissionais que respondem pelas tecnologias do livro e pelo percurso dele do autor ao leitor, no meio impresso ou no digital.

\section{Referências}

BORGES, Jorge Luis. Outras inquisições (1952). Tradução: Davi Arrigucci Jr. São Paulo: Cia das Letras, 2012.

CHARTIER, Roger. Um mundo sem livros e sem livrarias? Edição: Guiomar de Grammont. 1. ed. São Paulo: Letraviva, 2020.

FREIRE, Paulo. A importância do ato de ler. São Paulo: Cortez, 1989.

MARIN, Louis. Des pouvoirs de l'image: gloses. Paris: Editions du Seuil, 1993. 